alone, LESU $200 \mathrm{mg}+\mathrm{XOI}$, and LESU $400 \mathrm{mg}+\mathrm{XOI}$, respectively. Renal-related TEAE rates in the core studies were $5.6,7.3$, and 15.4 per 100 PY, respectively. Longer exposure in the core + extension studies did not result in increases in any TEAEs, serious TEAEs, or TEAEs leading to discontinuation (Table 2). MACE rates were low in the core + extension studies, at $1.05(95 \% \mathrm{Cl} 0.50,1.93)$ and $1.48(0.81,2.48)$ in the LESU $200 \mathrm{mg}+\mathrm{XOI}$ and LESU $400 \mathrm{mg}+\mathrm{XOI}$ groups, respectively. Renal events in the core + extension studies were lower in the LESU $200 \mathrm{mg}+\mathrm{XOI}$ than LESU $400 \mathrm{mg}+\mathrm{XOI}$ group at 8.6 and 14.6 , respectively. Conclusions: Lesinurad at the approved dose of $200 \mathrm{mg}$ once daily demonstrated a consistent, acceptable safety profile. There were no new safety concerns in the extension studies.

Acknowledgements: This study was funded by Ardea Biosciences/AstraZeneca. Disclosure of Interest: M. Becker Grant/research support from: Takeda, Savient, Ardea/AstraZeneca, Consultant for: Takeda, Savient, Horizon, Ardea/AstraZeneca, CymaBay, Pfizer, R. Keenan Consultant for: AstraZeneca, Ironwood, Horizon, P. Khanna Grant/research support from: AstraZeneca, R. Malamet Employee of: AstraZeneca, K. Bos Employee of: AstraZeneca, J. Li Employee of: AstraZeneca, J. Hu Employee of: Ardea Biosciences, W. White Consultant for: AstraZeneca

DOI: 10.1136/annrheumdis-2017-eular.3674

\section{THU0445 GOUTY ARTHRITIS: DECISION MAKING FOLLOWING DUAL ENERGY CT SCAN IN CLINICAL PRACTICE, A RETROSPECTIVE ANALYSIS}

M. Gamala ${ }^{1}$, S. Linn-Rasker ${ }^{2}$, M. Nix ${ }^{2}$, B. Heggelman ${ }^{2}$, J. van Laar ${ }^{1}$ P. Pasker-de Jong ${ }^{2}$, J. Jacobs ${ }^{1}$, R. Klaasen ${ }^{2} .{ }^{1}$ University Medical Center, Utrecht: ${ }^{2}$ Meander Medical Centre, Amersfoort, Netherlands

Background: Gout is associated with joint damage, and increased cardiovascular morbidity; it is important to diagnose and treat it. However, although clinical presentation may be strongly suggestive of gout, joint aspiration and microscopy not always yield the diagnosis. The latest technique to visualize monosodium uric acid MSU depositions and thus to diagnose gout is Dual Energy CT scan (DECT). ${ }^{1}$

Objectives: To establish whether DECT is a diagnostic tool, i.e. associated with initiation or discontinuation of a urate lowering drug (ULD). Second, whether DECT results (gout deposition $\mathrm{y} / \mathrm{n}$ ) can be predicted by clinical and laboratory variables.

Methods: Digital medical records of 147 consecutive patients with clinical suspicion of gout at the outpatient clinic of the Department of Rheumatology of Meander Medical Centre, Amersfoort, the Netherlands who underwent DECT between January 1, 2013 and December 31, 2014 were analyzed retrospectively. Collected were clinical data including medication before and after DECT, lab results, and results from diagnostic joint aspiration and DECT. The relationship between DECT results and clinica, and laboratory results was evaluated by univariate regression analyses; predictors showing a $p<0.10$ were entered in a multivariate logistic regression model with the DECT result as outcome variable. A manual backward stepwise technique was applied.

Results: 87 patients were diagnosed with gout based on demonstration of MSU crystals in synovial fluid (SF) or positive DECT result. In 30 patients, DECT was the only conformation of gout; in 29 of them ULD was started and in 1 it was intensified. Following DECT, the current ULD was stopped in 3 patients. The clinical and laboratory variables associated with the DECT result are presented in table 1. In the multivariable regression model, cardiovascular disease $\mathrm{y} / \mathrm{n}$ (OR $3.07,95 \% \mathrm{Cl} 1.26-7.47$ ), disease duration in years (OR 1.008, 95\% Cl 1.0011.016), frequency of attack per year (OR $1.23,95 \% \mathrm{Cl} 1.07-1.42$ ), creatinine clearance in $\mathrm{ml} / \mathrm{min}(\mathrm{OR} 2.03,95 \% \mathrm{Cl} 0.91-1.00)$ were independently associated with positive DECT results.

Table 1. Univariate model analyses of predictors of positive DECT results

\begin{tabular}{lcc}
\hline & OR $(95 \% \mathrm{Cl})$ & $\mathrm{p}$ \\
\hline Gender (reference: male gender) & $0.48(0.24-0.99)$ & 0.04 \\
Body Mass Index (per $\left.\mathrm{kg} / \mathrm{m}^{2}\right)$ & $1.03(0.96-1.11)$ & 0.36 \\
Cardiovascular disease yes/no & $2.72(1.36-5.42)$ & 0.04 \\
Diabetes mellitus yes/no & $3.69(1.26-10.71)$ & 0.01 \\
Urate lowering therapy use at the moment of DECT yes/no & $2.6(1.15-6.28)$ & 0.02 \\
Disease duration years & $1.01(1.005-1.02)$ & 0.01 \\
Frequency of attacks per year & $1.2(1.08-1.33)$ & 0.01 \\
Uric acid levels between flares (per $\mu \mathrm{mol} / \mathrm{L})$ & $1.004(1.001-1.007)$ & 0.008 \\
Creatinine clearance $($ per $\mathrm{ml} / \mathrm{min})$ & $0.95(0.92-0.99)$ & 0.01 \\
Joint involvement at the moment of DECT: MTP1 or other joints & $1.69(1.05-3.37)$ & 0.1 \\
Past first metatarsophalangeal (MTP1) joint involvement yes/no & $3.37(1.69-6.72)$ & 0.01 \\
MSU crystals at microscopy yes/no & $1.62(1.23-2.17)$ & 0.001 \\
\hline
\end{tabular}

Conclusions: DECT has impact on clinical decisions on ULD therapy. It may be a useful diagnostic imaging tool for patients who cannot undergo joint aspiration because of contraindications or with difficult to aspirate joints, or those who refuse joint aspiration.

References:

[1] Choi HK et al. Dual energy CT in gout: a prospectieve validation study. Ann Rheum Dis 2012; 71:1466-71.

Disclosure of Interest: None declared

DOI: 10.1136/annrheumdis-2017-eular.1881

\section{THU0446 PREVALENCE AND INCIDENCE OF NON-GOUT CRYSTAL ARTHROPATHY IN SOUTHERN SWEDEN FROM THE SOCIOECONOMIC PERSPECTIVE}

M. Hameed ${ }^{1}$, A. Turkiewicz ${ }^{2}$, T. Saxne ${ }^{3}$, L. Jacobsson ${ }^{4}$, M. Englund ${ }^{5}$, M.C. Kapetanovic ${ }^{6} .{ }^{1}$ Department of Clinical Sciences, Lund, Section for Rheumatology, Lund University, Lund and Skåne University Hospital, Section for Rheumatology in Lund and Malmö, Sweden, Malmö; ' 2 Lund University, Faculty of Medicine, Department of Clinical Sciences Lund, Orthopedics, Clinical Epidemiology Unit, Lund, Sweden; ${ }^{3}$ Department of Clinical Sciences, Lund, Section for Rheumatology, Lund University, Lund, Section for Rheumatology in Lund and Malmö, Lund; ${ }^{4}$ Department of Rheumatology \& Inflammation Research, Institute of Medicine, The Sahlgrenska Academy, University of Gothenburg, Gothenburg; ${ }^{5}$ Lund University, Faculty of Medicine, Department of Clinical Sciences Lund, Orthopedics, Clinical Epidemiology Unit; ${ }^{6}$ Department of Clinical Sciences, Lund, Section for Rheumatology, Lund University, Lund and Skåne University Hospital, Section for Rheumatology in Lund and Malmö, Sweden, Lund, Sweden

Background: Recently, we reported the prevalence of gout to be $1.7 \%$ among adults in the Skåne region in southern Sweden (1). Few epidemiological data are available on non-gout crystal arthropathy and none for this region.

Objectives: The objective of this study was to study the prevalence and incidence of non-gout crystal arthropathy (including chondocalcinosis, acute/subacute/chronic calcium pyrophosphate/hydroxyapatite or other crystal deposition disease) in southern Sweden from the socioeconomic perspective. Methods: The Skåne Healthcare Register includes information on all health care visits with given ICD10-coded diagnoses for all citizens in the region (total population 1.3 million). SHR was searched for all adult ( $\geq 18$ years) residents in Skåne region in year 2014, who between 1998 and 2014 had received at least one diagnosis of non-gout crystal arthropathy (ICD-10 code M11.0- M11.9) by any physician. The crude point prevalence at December 31st 2014 and the cumulative incidence in the calendar year 2014 were calculated. In addition, we examined the 2014 age- and sex- standardized point prevalence and cumulative incidence of non-gout crystal arthropathy according to occupation (white collar /blue collar with high or low skilled occupations), income (low/middle/high) and level of education (primary school/high school/university).

Results: The crude 2014 point prevalence and 2014 cumulative incidence $(95 \% \mathrm{Cl})$ of non-gout crystal arthropathy were $0.23 \%(0.22 \%-0.24 \%)$ and 21.5 (18.6-24.3) cases per 100000 persons at risk, respectively. Compared to women, men had numerically but not significantly higher prevalence $(0.26 \%$ vs $0.20 \%$ ) and incidence (24.6 vs 18.5 per 100000 persons). This pattern remained regardless of age. The mean (SD) age of a person with prevalent non-gout crystal arthropathy was 71.5 (14.4) years. Both prevalence and incidence increased with increasing age and were highest in individuals $>85$ years (prevalence $1.4 \%$ ), but decreased with years of education. Persons with middle income and blue collar high skilled occupation (e.g. skilled agricultural, forestry and fishery workers and craft and related trades workers) had the highest point prevalence and incidence of non-gout crystal arthroplasty (figure).
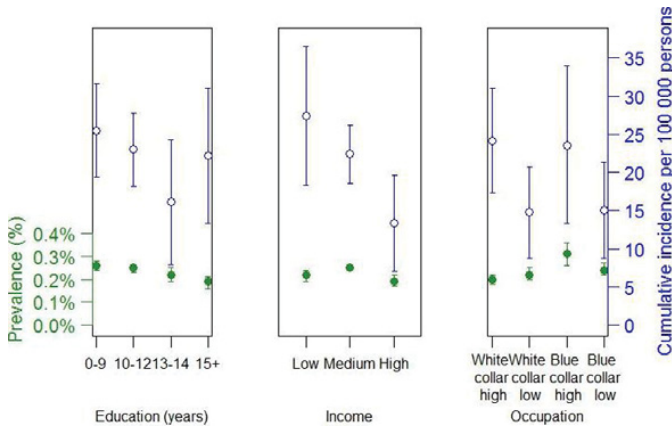

Conclusions: Although considerably less prevalent than gout in southern Sweden non-gout crystal arthropathy affects about $0.2 \%$ of the adult population, i.e. a similar prevalence as for psoriatic arthritis in the same region. The prevalence increases with age and is highest among individuals aged 85 years or higher. There is a socioeconomic gradient with more affected individuals among people with lower level of education, middle income, and more manual work.

References:

[1] Kapetanovic MC, Hameed M, Turkiewicz A, at al. Prevalence and incidence of gout in southern Sweden from the socioeconomic perspective. RMD Open. 2016 Nov 1;2(2):e000326. eCollection 2016.

Disclosure of Interest: None declared

DOI: 10.1136/annrheumdis-2017-eular.3089 